\title{
Porous structure and thermal properties of carbon adsorbents from pitch-polymer compositions
}

\author{
Grzegorz Makomaski ${ }^{1}$
}

Received: 31 October 2017 / Accepted: 14 March 2018/Published online: 23 March 2018

(C) The Author(s) 2018

\begin{abstract}
The study results of porous structure and thermal properties of carbon adsorbents (AC) obtained from pitch-polymer compositions were presented. The compositions were carbonized and activated with steam, potassium hydroxide, and magnesium and potassium carbonates. For the obtained AC, the thermal analysis and the determination of adsorption value of iodine and porous structure by adsorption/desorption of nitrogen at $77 \mathrm{~K}$ were carried out. The possibility of obtained activated carbons from pitch-polymer compositions was demonstrated. The use of untypical feedstock, as an effect of combination of bituminous substance with polymeric waste and improvement of the methods of production, creates the potential possibility to produce carbon adsorbents of interesting properties and porous structure.
\end{abstract}

Keywords Pitch-polymer compositions · Carbon adsorbents · DSC · Porous structure

\section{Introduction}

Carbon adsorbents, because of good mechanical durability, well-developed specific surface area and good sorption properties, from both gaseous and liquid phases, have found a widespread use in many branches of industry [1].

Activated carbons have been obtained from hard coal, lignite, wood, peat, fruit stones, coffee industry waste materials, waste tires, peel and shells [2-10]. Literature data show that some natural polymers, such as cellulose, as well as synthetic polymers and their waste, can be used for the production of activated carbons [11]. Laszlo and Szucs [12] obtained from poly(ethylene terephthalate) an carbon adsorbents of specific surface area $1170 \mathrm{~m}^{2} \mathrm{~g}^{-1}$ and total volume of pores $0.63 \mathrm{~cm}^{3} \mathrm{~g}^{-1}$, useful for adsorption of chlorophenols from waste waters. Similarly, from waste poly(ethylene terephthalate), through activation with $\mathrm{ZnCl}_{2}$ or $\mathrm{H}_{2} \mathrm{SO}_{3}$, Kartel et al. [13, 14] have obtained carbon adsorbents of specific surface area up to $1030 \mathrm{~m}^{2} \mathrm{~g}^{-1}$. In yet other papers $[15,16]$, it has been reported that novolac

Grzegorz Makomaski

Grzegorz.Makomaski@pw.edu.pl

1 Faculty of Civil Engineering, Mechanics and Petrochemistry, Warsaw University of Technology, Lukasiewicza 17, 09-400 Plock, Poland resin mixed with hexamethylenetetramine and poly(vinylbutyral) or poly(oxyethylene)diol can be applied in the preparation of activated carbons having specific surface area up to $1610 \mathrm{~m}^{2} \mathrm{~g}^{-1}$.

The use of polymer waste for the preparation of carbon adsorbents by thermal-chemical processes is interesting from a cognitive and utilitarian viewpoint. However, the obtainment of good activated carbons depends on high coking value of the feedstock, its adequate physical state and repeatability of properties. Most polymer wastes do not meet these requirements. That is why it is purposeful to mix polymer wastes with bituminous substances (e.g., coaltar pitch). Coal-tar pitch causes the increase in the amount of residue after carbonization or activation process, while polymer causes the increase in the surface area of carbon adsorbents. Obtaining carbon adsorbent from bitumenpolymer materials with the use of polymer waste can be an alternative direction to their recycling and the possibility to obtain good quality carbon adsorbents constituting a valuable complement to the current market offer.

At the Institute of Chemistry, Warsaw University of Technology in Plock, have been being carried out studies on bitumen-polymeric materials for several years. They are aimed at the improvement of utility properties of coaloriginated bitumen and utilization of waste polymers [17-20]. It was demonstrated that pitch-polymer 
compositions can be used for the preparation of carbon adsorbents [21-23] and mineral-carbon adsorbents [24, 25].

This paper presents the results of studies of porous structure and thermal properties of carbon adsorbents obtained from pitch-polymer compositions in the activation with steam, potassium hydroxide, magnesium and potassium carbonates. A novelty in the conducted research was the preparation of activated carbons from pitch-polymer compositions in the process of activation with magnesium carbonate and potassium carbonate.

\section{Experimental procedures}

The raw materials used in this study were pitch-polymer compositions containing (1:1 by mass) coal-tar pitch (CTP) and wastes poly(ethylene terephthalate) (PET), phenolformaldehyde resin (PF) or poly(methylene methacrylate) (PMMA). Pitch-polymer compositions were prepared in the conditions allowing to obtain homogeneous and stable mixtures: pitch-PET composition (CTP-PET) obtained at $260{ }^{\circ} \mathrm{C}$, during $0.5 \mathrm{~h}$, pitch-PF composition (CTP-PF) obtained at $150{ }^{\circ} \mathrm{C}$, during $2.5 \mathrm{~h}$, and pitchPMMA composition (CTP-PMMA) obtained at $270{ }^{\circ} \mathrm{C}$, during $1 \mathrm{~h}$ [26].

Pitch-polymer compositions were carbonized and activated with steam, potassium hydroxide and magnesium carbonate or potassium carbonate (Fig. 1).
Carbonization was carried out in two stages:

- phase one of initial carbonization, performed by heating the sample to the temperature of $520{ }^{\circ} \mathrm{C}$ at the heating rate of $5 \mathrm{~K} \mathrm{~min}^{-1}$, in nitrogen atmosphere and annealing it in this temperature for $1 \mathrm{~h}$,

- phase two, executed in a horizontal furnace by heating the sample to the temperature of $520^{\circ} \mathrm{C}$ with the heating rate of $15 \mathrm{~K} \mathrm{~min}^{-1}$, and then to $850{ }^{\circ} \mathrm{C}$ with the heating rate of $10 \mathrm{~K} \mathrm{~min}^{-1}$. The sample was annealed at $850{ }^{\circ} \mathrm{C}$ for $1 \mathrm{~h}$.

The products of carbonization were activated with steam at $800{ }^{\circ} \mathrm{C}$, to $50 \%$ burn-off.

Additionally, for prepared pitch-polymer compositions also the process of carbonization and chemical activation with $\mathrm{KOH}$ was carried out. In this case, samples were initially carbonized at $520{ }^{\circ} \mathrm{C}$ and subsequently chemically activated. The mixture of pulverized $\mathrm{KOH}$ and the product of initial carbonization (mass ratio of $3: 1$ ) was heated to the temperature of $800^{\circ} \mathrm{C}$ with the heating rate of $10 \mathrm{~K} \mathrm{~min}^{-1}$ and then annealed in this temperature for $1 \mathrm{~h}$. The process was carried out in nitrogen atmosphere. Furthermore, pitch-polymer compositions were activated with carbonates $\left(\mathrm{K}_{2} \mathrm{CO}_{3}\right.$ or $\left.\mathrm{MgCO}_{3}\right)$. The mixtures consisting of pitchpolymer compositions and $\mathrm{K}_{2} \mathrm{CO}_{3}$ or $\mathrm{MgCO}_{3}$ (mass ratio 3:7) were heated in air to $270{ }^{\circ} \mathrm{C}$, cooled and again heated to $270{ }^{\circ} \mathrm{C}$. Next, the mixtures were activated in nitrogen flow at $850{ }^{\circ} \mathrm{C}$ for $1 \mathrm{~h}$. The heating rate was $10 \mathrm{~K} \mathrm{~min}^{-1}$. Product of activation with $\mathrm{KOH}, \mathrm{K}_{2} \mathrm{CO}_{3}$ or $\mathrm{MgCO}_{3}$ was
Fig. 1 Diagram of preparation of carbon adsorbents from pitch-polymer compositions

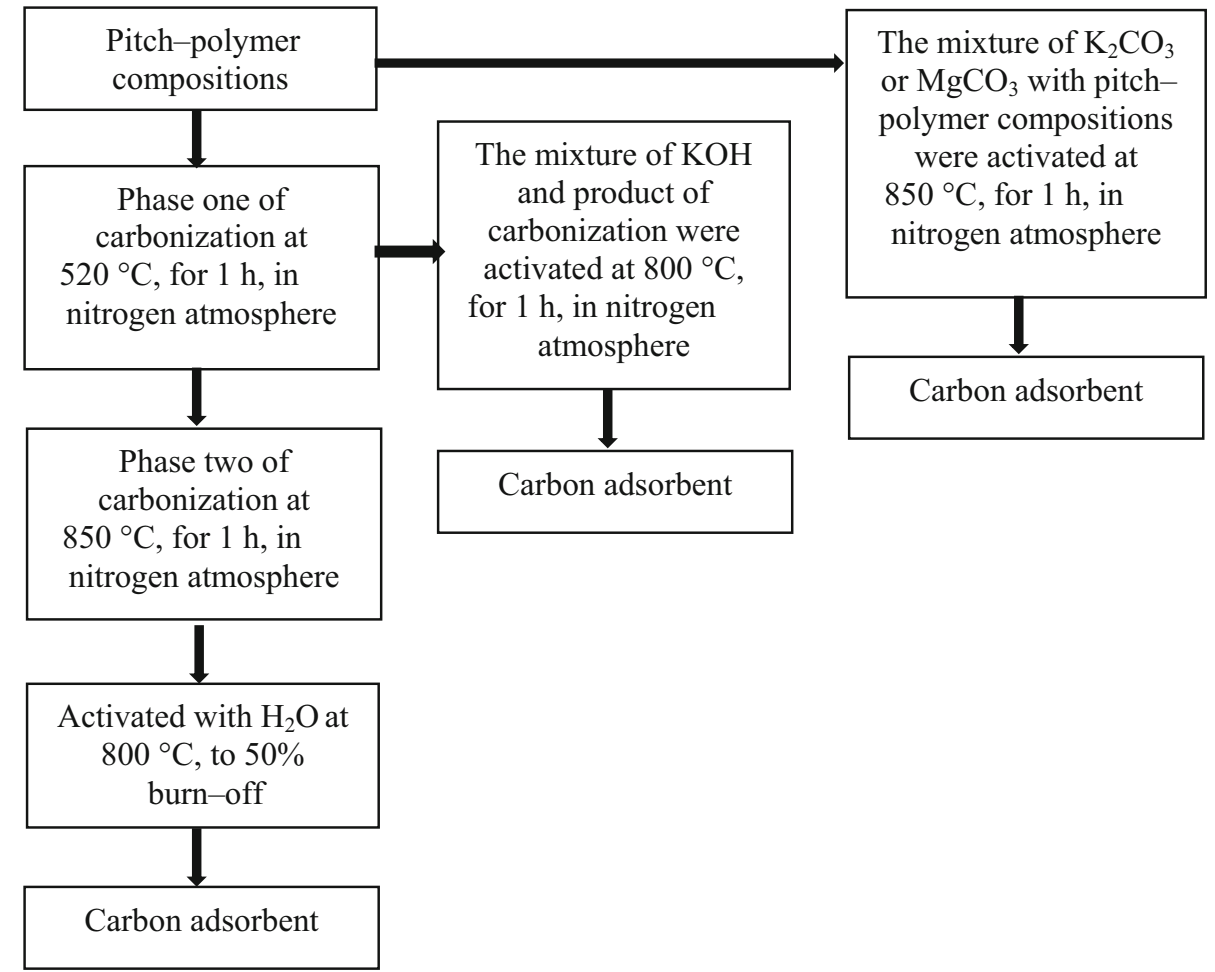


rinsed with distilled water, $10 \% \mathrm{HCl}$ till a neutral reaction. Obtained carbon adsorbents were dried at $105^{\circ} \mathrm{C}$ for $12 \mathrm{~h}$ in air.

For obtained carbon adsorbents, the following parameters were determined: thermal properties by the thermal analysis. Scanning differential calorimetry curves were recorded by means of scanning differential calorimeter Netzsch Maia F3 on heating up to $250{ }^{\circ} \mathrm{C}$ with a rate of $10 \mathrm{~K} \mathrm{~min}^{-1}$ in nitrogen atmosphere (samples mass about $6 \mathrm{mg}$ ). Thermogravimetric curves (TG and DTG) were recorded by means of Derivatograph-C (produced by MON Budapest) on heating up to $750{ }^{\circ} \mathrm{C}$ with a rate of $10 \mathrm{~K} \mathrm{~min}^{-1}$ in nitrogen atmosphere (sample mass $19.5 \mathrm{mg}$ ). The sorption properties of obtained carbon adsorbents were characterized by adsorption value of iodine (IN) according to PN-C-97555.03:1982. Pore parameters in the obtained carbon adsorbents were evaluated from the adsorption/desorption isotherms of nitrogen gas at $77 \mathrm{~K}$. Specific surface are $\left(S_{\mathrm{BET}}\right)$ was determined by the Brunauer-Emmett-Teller method. The micropore volume $\left(V_{\text {mic }}\right)$ was determined by Dubinin-Radushkevich method, and mesopore volume $\left(V_{\text {mes }}\right)$ was determined by Barrett-Joyner-Halenda method.

\section{Results and discussion}

Table 1 contains sorption properties and parameters of porous structure of obtained carbon adsorbents.

The type of composition and activation agent influenced the sorption capacity of carbon adsorbents (Table 1). While assessing the efficiency of applied activating agents on sorption properties of carbon adsorbents obtained from pitch-polymer compositions, it was found that activated carbons obtained in the process of activation with $\mathrm{KOH}$ had significantly higher values of adsorption of iodine (above $2100 \mathrm{mg} \mathrm{g}^{-1}$ ) than carbon adsorbents prepared in the process of activation with steam, potassium carbonate or magnesium carbonate. In addition, the obtained carbon adsorbents in the potassium hydroxide activation process have similar IN values.

Among carbon adsorbents obtained by steam activation, the highest $I N$ value $\left(1050 \mathrm{mg} \mathrm{g}^{-1}\right.$ ) was characterized by activated carbon AC CTP-PF $\left(\mathrm{H}_{2} \mathrm{O}\right)$, while the smallest IN value $\left(700 \mathrm{mg} \mathrm{g}^{-1}\right)$ was characterized by activated carbon AC CTP-PMMA $\left(\mathrm{H}_{2} \mathrm{O}\right)$. In the case of carbon adsorbents obtained by the potassium carbonate activation process, the highest IN value (990 $\mathrm{mg} \mathrm{g}^{-1}$ ) was observed for activated carbon $\mathrm{AC}$ CTP-PF $\left(\mathrm{K}_{2} \mathrm{CO}_{3}\right)$, while the smallest IN value (780 $\mathrm{mg} \mathrm{g}^{-1}$ ) was observed for carbon adsorbent $\mathrm{AC}$ CTP-PET $\left(\mathrm{K}_{2} \mathrm{CO}_{3}\right)$. Among the carbon adsorbents obtained by the magnesium carbonate activation process, the highest IN value $\left(750 \mathrm{mg} \mathrm{g}^{-1}\right)$ was observed for activated carbon AC CTP-PET $\left(\mathrm{MgCO}_{3}\right)$, while the smallest IN value (430 $\mathrm{mg} \mathrm{g}^{-1}$ ) was observed for carbon adsorbent $\mathrm{AC}$ CTP-PMMA $\left(\mathrm{MgCO}_{3}\right)$.

Molecule of iodine is quite small; it is a good indicator for the adsorption capacity an activated carbon. It is a measure of the micropore content of the activated carbon. The results of adsorption value of iodine (Table 1) showed that carbon adsorbents obtained in the process of activation with $\mathrm{KOH}$ had significantly the higher micropore content than carbon adsorbents prepared in the process of activation with steam, potassium carbonate or magnesium carbonate. In addition, a correlation was observed between the adsorption value of iodine and porous structure of carbon
Table 1 Sorption properties and parameters of porous structure of obtained carbon adsorbents from pitch-polymer compositions

\begin{tabular}{|c|c|c|c|c|}
\hline Carbon adsorbents & $I N / \mathrm{mg} \mathrm{g}^{-1}$ & $S_{\mathrm{BET}} / \mathrm{m}^{2} \mathrm{~g}^{-1}$ & $V_{\mathrm{mic}} / \mathrm{cm}^{3} \mathrm{~g}^{-1}$ & $V_{\text {mes }} / \mathrm{cm}^{3} \mathrm{~g}^{-1}$ \\
\hline \multicolumn{5}{|l|}{ Activation with steam } \\
\hline AC CTP-PET $\left(\mathrm{H}_{2} \mathrm{O}\right)$ & 1020 & 1042 & 0.381 & 0.040 \\
\hline AC CTP-PF $\left(\mathrm{H}_{2} \mathrm{O}\right)$ & 1050 & 1120 & 0.393 & 0.056 \\
\hline AC CTP-PMMA $\left(\mathrm{H}_{2} \mathrm{O}\right)$ & 700 & 401 & 0.152 & 0.036 \\
\hline \multicolumn{5}{|c|}{ Activation with potassium hydroxide } \\
\hline AC CTP-PET(KOH) & 2110 & 3265 & 1.060 & 0.328 \\
\hline AC CTP-PF(KOH) & 2160 & 3345 & 1.062 & 0.258 \\
\hline AC CTP-PMMA(KOH) & 2190 & 3134 & 1.017 & 0.162 \\
\hline \multicolumn{5}{|c|}{ Activation with potassium carbonate } \\
\hline AC CTP-PET $\left(\mathrm{K}_{2} \mathrm{CO}_{3}\right)$ & 780 & 1049 & 0.401 & 0.486 \\
\hline $\mathrm{AC} \mathrm{CTP-PF}\left(\mathrm{K}_{2} \mathrm{CO}_{3}\right)$ & 990 & 715 & 0.276 & 0.066 \\
\hline AC CTP-PMMA $\left(\mathrm{K}_{2} \mathrm{CO}_{3}\right)$ & 960 & 1142 & 0.438 & 0.074 \\
\hline \multicolumn{5}{|c|}{ Activation with magnesium carbonate } \\
\hline AC CTP-PET( $\left.\mathrm{MgCO}_{3}\right)$ & 750 & 577 & 0.208 & 0.496 \\
\hline AC CTP-PF $\left(\mathrm{MgCO}_{3}\right)$ & 430 & 316 & 0.083 & 0.117 \\
\hline AC CTP-PMMA( $\left.\mathrm{MgCO}_{3}\right)$ & 610 & 289 & 0.104 & 0.142 \\
\hline
\end{tabular}


adsorbents. Activated carbons having the highest of $I N$ values were characterized by the highest $S_{\mathrm{BET}}$ and total pore volume.

The type of composition and the type of activating agent had been effect on the porous texture of the carbon adsorbents from pitch-polymer compositions. It has been shown that in the case of carbon adsorbents obtained by steam activation, the highest $S_{\mathrm{BET}}, V_{\text {mic }}$ and $V_{\text {mes }}$ were characterized by activated carbon AC CTP-PF $\left(\mathrm{H}_{2} \mathrm{O}\right)$, while the smallest $S_{\mathrm{BET}}, V_{\text {mic }}$ and $V_{\text {mes }}$ were characterized by carbon adsorbent AC CTP-PMMA $\left(\mathrm{H}_{2} \mathrm{O}\right)$.

Among the carbon adsorbents obtained by the $\mathrm{KOH}$ activation process, the highest $S_{\mathrm{BET}}$ and $V_{\text {mic }}$ were observed for the activated carbon AC CTP-PF(KOH) obtained from composition containing 50 mass $\%$ of waste $\mathrm{PF}$. The highest volume of mesopores was observed for the adsorbent AC CTP-PET(KOH). The smallest $S_{\mathrm{BET}}, V_{\text {mic }}$ and $V_{\text {mes }}$ were observed for carbon adsorbents AC CTP$\operatorname{PMMA}(\mathrm{KOH})$.

In the case of carbon adsorbents obtained by the $\mathrm{K}_{2} \mathrm{CO}_{3}$ activation process, the highest $S_{\mathrm{BET}}$ and $V_{\text {mic }}$ were observed for activated carbon AC CTP-PMMA $\left(\mathrm{K}_{2} \mathrm{CO}_{3}\right)$, while the highest volume of mesopores was observed for activated carbon AC CTP-PET $\left(\mathrm{K}_{2} \mathrm{CO}_{3}\right)$. The smallest $S_{\mathrm{BET}}, V_{\text {mic }}$ and $V_{\text {mes }}$ were observed for carbon adsorbents AC CTP-PF $\left(\mathrm{K}_{2} \mathrm{CO}_{3}\right)$.

Among the carbon adsorbents obtained by the $\mathrm{MgCO}_{3}$ activation process, the highest $I N S_{\mathrm{BET}}, V_{\mathrm{mic}}$ and $V_{\text {mes }}$ were observed for the carbon adsorbents AC CTPPET $\left(\mathrm{MgCO}_{3}\right)$. The smallest $S_{\mathrm{BET}}$ was observed for the carbon adsorbent AC CTP-PMMA $\left(\mathrm{MgCO}_{3}\right)$, while the smallest volume of micropores and mesopores was observed for carbon adsorbent AC CTP-PF $\left(\mathrm{MgCO}_{3}\right)$.

It was found that the carbon adsorbent obtained by the activation with steam, $\mathrm{KOH}$ and $\mathrm{K}_{2} \mathrm{CO}_{3}$ (only for the activated carbons AC CTP-PF $\left(\mathrm{K}_{2} \mathrm{CO}_{3}\right)$ and AC CTP$\left.\operatorname{PMMA}\left(\mathrm{K}_{2} \mathrm{CO}_{3}\right)\right)$ had the microporous structure. Activate carbons obtained by the activation with $\mathrm{K}_{2} \mathrm{CO}_{3}$ (for the activated carbon AC CTP-PET $\left(\mathrm{K}_{2} \mathrm{CO}_{3}\right)$ ) and $\mathrm{MgCO}_{3}$ had the mesoporous structure. This is due to processes occurring between polymer macromolecules and group components of coal-tar pitch during carbonization and/or activation. Volatile products evolved in the process of high-temperature heat treatment of the compositions and secondary reactions, e.g., with activating agents, favorably affect the development of the porous structure of carbon adsorbents. In addition, selected polymer wastes contain oxygen in the structure of the chain that can promote dehydrogenation during carbonization and/or activation of the compositions. Probably, it positively affects the porous structure of carbon adsorbents.

Figure 2 presents the isotherms of adsorption and desorption of nitrogen gas at $77 \mathrm{~K}$ for studied carbon adsorbents. Adsorption/desorption isotherms of studied carbon adsorbents obtained by the activation with steam, $\mathrm{KOH}$ and $\mathrm{K}_{2} \mathrm{CO}_{3}$ (only for the activated carbons AC CTP$\mathrm{PF}\left(\mathrm{K}_{2} \mathrm{CO}_{3}\right)$ and AC CTP-PMMA $\left.\left(\mathrm{K}_{2} \mathrm{CO}_{3}\right)\right)$ belong to the I type, according to the IUPAC classification, i.e., they are typical for microporous materials. Activated carbons obtained by the activation with $\mathrm{K}_{2} \mathrm{CO}_{3}$ (for the activated carbon AC CTP-PET $\left(\mathrm{K}_{2} \mathrm{CO}_{3}\right)$ ) and $\mathrm{MgCO}_{3}$ belong to the IV type, typical for mesoporous materials. For the carbon adsorbents obtained by the activation with $\mathrm{KOH}$, adsorption capacity was higher than for the activated carbons obtained by the activation with steam, $\mathrm{K}_{2} \mathrm{CO}_{3}$ and $\mathrm{MgCO}_{3}$.

In Fig. 3, DSC curves of carbon adsorbents obtained from pitch-polymer compositions by the activation with steam, potassium hydroxide, magnesium carbonate or potassium carbonate are shown. Analyzing the courses of DSC curves of carbon adsorbents, only endothermic transition occurring in the range of temperatures from 32.7 to $61.7{ }^{\circ} \mathrm{C}$ (enthalpy values from -2.856 to $-32.840 \mathrm{~J} \mathrm{~g}^{-1}$ ) was observed. This transition is probably related to desorption of physically adsorbed water, probably occurred during storage. Furthermore, the hygroscopicity in carbon adsorbents can be related to the presence of oxygenated surface groups responsible for hydrogen bonds between the water and the oxygen molecules.

Based on DSC curves course for obtained activated carbons, the effect of the porous structure of carbon adsorbents on the values of desorption of water temperature was found. The highest values of desorption of water temperature were observed for carbon adsorbents $\mathrm{AC}$ CTP-PET $\left(\mathrm{K}_{2} \mathrm{CO}_{3}\right)$ and AC CTP-PET $\left(\mathrm{MgCO}_{3}\right)$. These carbon adsorbents had the mesoporous structure. The smallest desorption of water temperature (from 32.7 to $42.3^{\circ} \mathrm{C}$ ) was observed for activation with steam.

Therefore, thermogravimetric (TG) measurements were taken for carbon adsorbents AC CTP-PET $\left(\mathrm{K}_{2} \mathrm{CO}_{3}\right)$ (Fig. 4). Based on the course of TG and DTG curves of carbon adsorbent, two steps were observed. The first steps up to $115^{\circ} \mathrm{C}$ show mass loss for the carbon adsorbent about $2 \%$ due to the desorption of physically adsorbed water on the porous material. The endothermic transition on the DSC curve (max. peak $61.5^{\circ} \mathrm{C}$ ) occurred in the same range as the transitions occurring on the TG and DTG (max. peak $59.6{ }^{\circ} \mathrm{C}$ ). The decomposition product of the second mass loss steps can be assigned to the surface groups formed during the activation process, as well as to the carbon skeleton decomposition. Probably, in the second step groups such as carboxylic acids, carboxylic anhydrides and lactones, which are less thermally stable, decompose with the evolution of carbon dioxide between 300 and $400{ }^{\circ} \mathrm{C}$. 

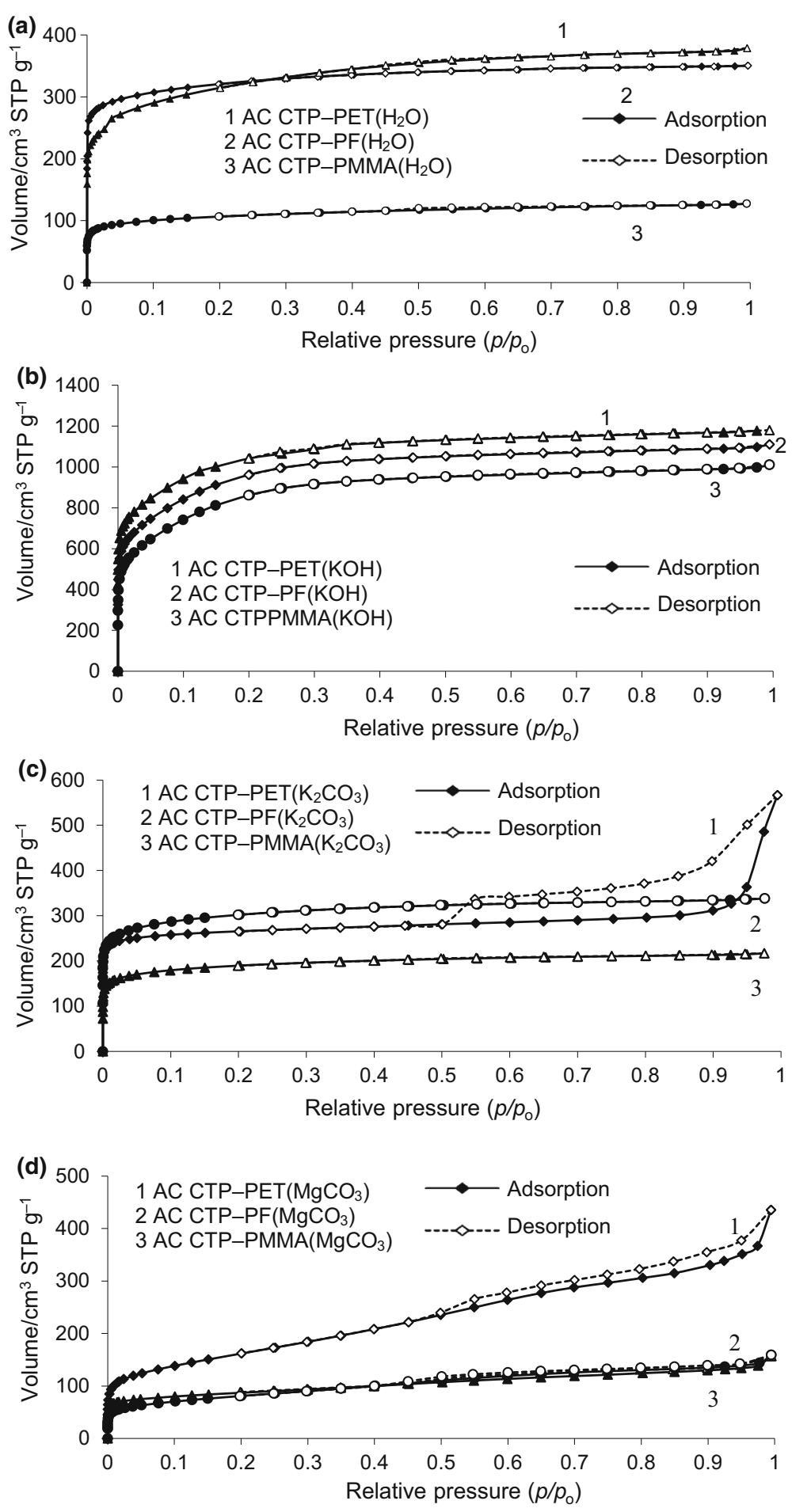

Fig. 2 Isotherms of adsorption/desorption of nitrogen vapor for obtained carbon adsorbents by activation with: a steam, b $\mathrm{KOH}_{\text {, }} \mathbf{c} \mathrm{K}_{2} \mathrm{CO}_{3}$, d $\mathrm{MgCO}_{3}$ 

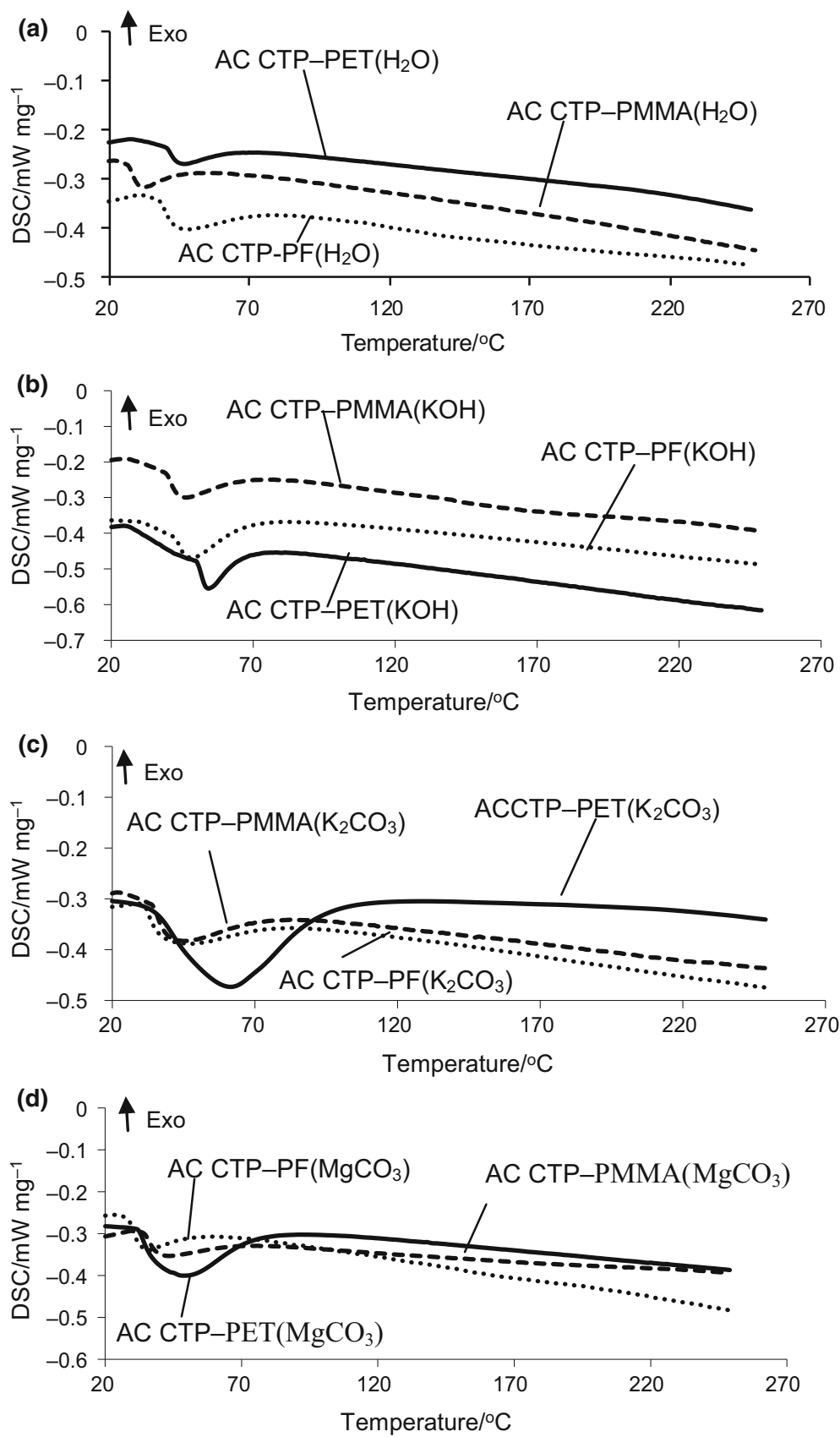

Fig. 3 DSC curves of carbon adsorbents by activation with: a steam, b $\mathrm{KOH}, \mathbf{c} \mathrm{K}_{2} \mathrm{CO}_{3}, \mathbf{d ~} \mathrm{MgCO}_{3}$ 


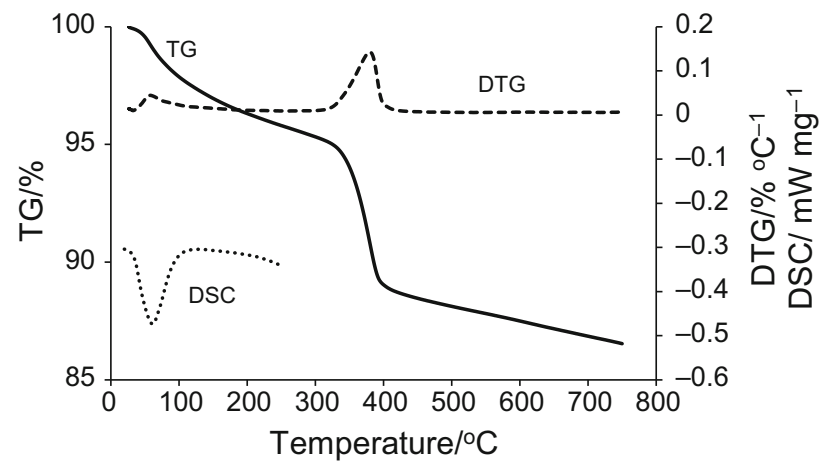

Fig. 4 TG, DTG and DSC curves of carbon adsorbent AC CTP$\operatorname{PET}\left(\mathrm{K}_{2} \mathrm{CO}_{3}\right)$

\section{Conclusions}

The use of untypical feedstock, as an effect of combination of bituminous substance with polymeric waste and improvement of the methods of production, creates the potential possibility to produce carbon adsorbents of interesting properties and porous structure.

The presence of the molecule of a polymer into coal-tar pitch beneficially influences the process of carbonization and/or activation and in effect the thermal properties, sorption capacity and porous structure of activated carbons. The sorption capacity and porous structure of activated carbons can also develop depending on the activating agents. It was found that activated carbons obtained in the process of activation with potassium hydroxide had significantly higher values of adsorption of iodine, specific surface are and micropore volume than those of carbon adsorbents prepared in the process of activation with steam, potassium carbonate or magnesium carbonate. Moreover, carbon adsorbent obtained by the activation with steam, $\mathrm{KOH}$ and $\mathrm{K}_{2} \mathrm{CO}_{3}$ (only for the activated carbons AC CTP$\mathrm{PF}\left(\mathrm{K}_{2} \mathrm{CO}_{3}\right)$ and AC CTP-PMMA $\left.\left(\mathrm{K}_{2} \mathrm{CO}_{3}\right)\right)$ had the microporous structure. Activate carbons obtained by the activation with $\mathrm{K}_{2} \mathrm{CO}_{3}$ (for the activated carbon AC CTP$\operatorname{PET}\left(\mathrm{K}_{2} \mathrm{CO}_{3}\right)$ ) and $\mathrm{MgCO}_{3}$ had the mesoporous structure.

The use of differential scanning calorimetry in the studies of activated carbons made possible the determination of water desorption temperature. The type of activating agents influenced the thermal properties of carbon adsorbents obtained from pitch-polymer compositions. It was found that mesoporous adsorbents obtained from pitch-PET compositions by the activation with $\mathrm{K}_{2} \mathrm{CO}_{3}$ or $\mathrm{MgCO}_{3}$ had higher capacity for the physical adsorption of water from air.

Open Access This article is distributed under the terms of the Creative Commons Attribution 4.0 International License (http://creative commons.org/licenses/by/4.0/), which permits unrestricted use, distribution, and reproduction in any medium, provided you give appropriate credit to the original author(s) and the source, provide a link to the Creative Commons license, and indicate if changes were made.

\section{References}

1. Marsh H, Rodriguez-Reinoso F. Activated carbon. Amsterdam: Elsevier; 2006.

2. Skubiszewska-Zięba J, Charmas B, Kołtowski M, Oleszczuk P. Active carbons from waste biochars. J Therm Anal Calorim. 2017;130:15-24.

3. Gonzalez T, Molina-Sabio M, Rodriguez-Reinoso F. Steam activation of olive stone chars, development of porosity. Carbon. 1994;32:1407-13.

4. Wu M, Shi L, Mi J. Preparation and desulfurization kinetics of activated carbons from semi-coke of coal liquefaction residual. J Therm Anal Calorim. 2017;129:1593-603.

5. Nowicki P. Effect of heat treatment on the physicochemical properties of nitrogen-enriched activated carbons. J Therm Anal Calorim. 2016;125:1017-24.

6. Nowicki P, Skibiszewska P, Pietrzak R. Hydrogen sulphide removal on carbonaceous adsorbents prepared from coffee industry waste materials. Chem Eng J. 2014;248:208-15.

7. SkibiszewskaP Nowicki P, Pietrzak R. $\mathrm{NO}_{2}$ removal on adsorbents prepared from coffee industry waste materials. Adsorption. 2013;19:521-8.

8. Hofman M, Pietrzak R. Adsorbents obtained from waste tires for $\mathrm{NO}_{2}$ removal under dry conditions at room temperature. Chem Eng J. 2011;170:202-8.

9. Salas-Enriguez BG, Torres-Huerta AM, Conde-Barajas E, Dominiguez-Crespo MA, Diaz-Garcia L, Negrete-Rodriguez M. Activated carbon production from the Guadua amplexifolia using a combination of physical and chemical activation. J Therm Anal Calorim. 2016;124:1383-98.

10. Giraldo L, Moreno-Pirajan JC. $\mathrm{CO}_{2}$ adsorption on activated carbon prepared from mangosteen peel. J Therm Anal Calorim. 2017. https://doi.org/10.1007/s10973-017-6725-2.

11. Ciesińska W, Makomaski G, Zieliński J, Brzozowska T. Preparation of sorbents from selected polymers. Pol J Chem Technol. 2011;13:51-4.

12. Laszlo K, Szucs A. Surface characterization of polyethyleneterephthalate (PET) based activated carbon and the effect of $\mathrm{pH}$ on its adsorption capacity from aqueous phenol and 2,3,4-trichlorophenol solutions. Carbon. 2001;39:1945-53.

13. Kartel M, Gerasimenko N, Tsyba M, Nikolaichuk A, Kovtun G. Synthesis and study of carbon sorbent prepared from polyethylene terephthalate. Russ J Appl Chem. 2001;74:1765-7.

14. Kartel M, Sych N, Tsyba M, Strelko V. Preparation of porous carbons by chemical activation of polyethylene terephthalate. Carbon. 2006;44:1019-22.

15. Yang J, Ling L, Liu L, Kang F, Huang Z, Wu H. Preparation and properties of phenolic resin-based activated carbon spheres with controlled pore size distribution. Carbon. 2002;40:911-6.

16. Cai Q, Huang Z, Kang F, Yang J. Preparation of activated carbon microspheres from phenolic-resin by supercritical water activation. Carbon. 2004:42:775-83.

17. Zieliński J, Osowiecka B, Liszyńska B, Ciesińska W, Polaczek J, Kubica K. Benzo[a]pyrene in coal tar pitch: chemical conversion in situ by alkylation. Fuel. 1996;75:1543-8.

18. Ciesińska W, Zieliński J, Brzozowska T. Thermal treatment of pitch-polymer blends. J Therm Anal Calorim. 2009;95:193-6.

19. Ciesińska W. Thermo-rheological properties of coal-tar pitch modified with phenol-formaldehyde resin. J Therm Anal Calorim. 2017:130:187-95. 
20. Makomaski G, Zieliński J. Thermal properties of group components of the pitch-PET compositions. J Therm Anal Calorim. 2017;130:329-34.

21. Makomaski G, Ciesińska W, Zieliński J. Thermal properties of pitch-polymer compositions and derived activated carbons. J Therm Anal Calorim. 2012;109:767-72.

22. Makomaski G. The preparation of porous materials from waste polymers-modified carbon bitumens. Przem Chem. 2016;95:1378-80.

23. Makomaski G, Zieliński J, Zdziarski M. Effect of some carbonization and activation parameters on the sorption properties of carbon adsorbents made by carbonization of pitch-polymer blends. Przem Chem. 2015;94:694-7.
24. Szychowski D, Pacewska B. Methods of preparation and properties of mineral-carbon sorbents obtained from coal-tar pitchpolymer compositions. J Therm Anal Calorim. 2012;109:789-95.

25. Szychowski D, Pacewska B, Makomaski G, Ciesińska W, Zieliński J. Adsorption and DSC study of mineral-carbon sorbents obtained from coal-tar pitch-polymer compositions. J Therm Anal Calorim. 2012;107:893-900.

26. Makomaski G. Study on the structure of pitch-polymer compositions by fluorescence microscope. Colloid Polym Sci. 2015;293:297-301. 